\title{
The Association between Sequences of Sexual Initiation and the Likelihood of Teenage Pregnancy
}

\author{
Bianka M. Reese, \\ Carolina Population Center and Department of Health Policy and Management, Gillings School of \\ Global Public Health, University of North Carolina at Chapel Hill, Chapel Hill, NC
}

\begin{abstract}
Abigail A. Haydon, Ph.D., APA Executive Branch Fellow, on assignment with the Eunice Kennedy Shriver National Institute of Child Health and Human Development, National Institutes of Health, Bethesda, Maryland
\end{abstract}

Amy H. Herring, Sc.D., and Carolina Population Center and Department of Biostatistics, Gillings School of Global Public Health, University of North Carolina at Chapel Hill, Chapel Hill, NC

Carolyn T. Halpern, Ph.D.

Carolina Population Center and Department of Maternal and Child Health, Gillings School of Global Public Health, University of North Carolina at Chapel Hill, Chapel Hill, NC

\section{Abstract}

Purpose-Few studies have examined the health and developmental consequences, including unintended pregnancy, of different sexual behavior initiation sequences. Some work suggests that engaging in oral-genital sex first may slow the transition to coital activity and lead to more consistent contraception among adolescents.

Methods-Using logistic regression analysis, we investigated the association between sequences of sexual initiation (i.e., initiating oral-genital or vaginal sex first based on reported ages of first experience) and the likelihood of subsequent teenage pregnancy among 6,069 females who reported vaginal sex before age 20 and participated in Waves I and IV of the National Longitudinal Study of Adolescent Health (Add Health).

Results-Among females initiating vaginal sex first, $31.4 \%$ reported a teen pregnancy. Among females initiating two behaviors at the same age, $20.5 \%$ reported a teen pregnancy. Among females initiating oral-genital sex first, $7.9 \%$ reported a teen pregnancy. In multivariate models, initiating oral-genital sex first, with a delay of at least one year to vaginal sex, and initiating two behaviors within the same year were each associated with a lower likelihood of adolescent

\footnotetext{
(C) 2012 Society for Adolescent Medicine. Published by Elsevier Inc. All rights reserved

Address Correspondence to Bianka Reese, Carolina Population Center, CB \# 8120, University of North Carolina, Chapel Hill, NC, USA 27516-2524. Phone: (919)358-8949. Fax: (919) 966-6638. bmreese@live.unc.edu.

Publisher's Disclaimer: This is a PDF file of an unedited manuscript that has been accepted for publication. As a service to our customers we are providing this early version of the manuscript. The manuscript will undergo copyediting, typesetting, and review of the resulting proof before it is published in its final citable form. Please note that during the production process errors may be discovered which could affect the content, and all legal disclaimers that apply to the journal pertain.

Implications and Contribution Statement

It is important to identify behavioral patterns that reduce the odds of teen pregnancy. This study's findings are the first to demonstrate in a representative US sample that the sequence of initiating different types of sexual behaviors is associated with the likelihood of teen pregnancy, offering a potential avenue for intervention.

None of the authors has a conflict of interest related to this work.
} 
pregnancy, relative to teens who initiated vaginal sex first $(\mathrm{OR}=0.23,95 \% \mathrm{CI}(0.15,0.37)$ and $\mathrm{OR}=0.78,95 \% \mathrm{CI}(0.60,0.92)$, respectively).

Conclusions-How adolescents begin their sexual lives may be differentially related to positive and negative health outcomes. To develop effective pregnancy prevention efforts for teens and ensure programs are relevant to youths' needs, it is important to consider multiple facets of sexual initiation and their implications for adolescent sexual health and fertility.

\section{Introduction}

Although there has been a significant decline in rates over the past 20 years, teen pregnancy remains a serious public health issue in the United States (1). With about 750,000 pregnancies, or 71.5 pregnancies per 1,000 women under 20 each year, the teen pregnancy rate in the US remains substantially higher than those of other developed countries (2). Teen pregnancy brings significant social and economic costs through both immediate and longterm impacts on teen parents and their children. For instance, according to the Centers for Disease Control and Prevention, only about 50\% of teen mothers obtain a high school diploma by age 22 , compared with $90 \%$ of teen girls who did not give birth (2).

Additionally, teen childbearing costs US taxpayers about $\$ 9$ billion each year in increased costs for health care, child welfare, and lost tax revenue (3).

Most research on adolescent sexual behavior has focused on vaginal intercourse. Although first vaginal intercourse is clearly an important transition, adolescents engage in other types of sexual behavior, like oral-genital sex, that also have implications for health and wellbeing. More than half of adolescents (ages 15-19) have ever received or performed oralgenital sex, and incidence increases with age and vaginal intercourse experience (4-6). Many teens perceive fewer health, social, and emotional risks for oral-genital versus vaginal sex, most notably the elimination of pregnancy risk. Teens may also view oral-genital sex as more acceptable, even outside the context of a romantic relationship (7-10). For some teens, oral sex may be seen as an alternative to vaginal intercourse, allowing more frequent and/or non-romantic sexual contact without compromising traditional definitions of virginity (11-13). On the other hand, adolescents who experience oral sex are also less likely to report sexual pleasure relative to their peers with coital experience (21), and teens may not recognize that oral sex can still act as a mode of transmission for sexually transmitted infections (STIs) and thus may not use barrier protection while receiving or performing oralgenital sex (8-9,14-15).

There are few studies that have examined the prevalence of varying sexual sequences (i.e., the order and timing of initiating different types of sex) among adolescents and even fewer that explore whether these sequences have health implications. Studies that examine sequences of initiation directly have noted that most adolescents, especially white teens, progress from less intimate (e.g., kissing) to more intimate (e.g., coitus) behaviors (16-19). Song and Halpern-Felsher (8), in their longitudinal analysis of approximately 600 California high school students, reported that more sexually active adolescents initiated oral-genital and vaginal sex within the same 6-month period, and that oral sex typically occurred first. If oral sex experience occurred early in high school, odds of early vaginal sex increased (8).

However, other work suggests that a "linear" sequence of progression from less to more intimate behaviors may delay transition to coitus (7). Further, linear sequences have been associated with positive outcomes, such as consistent contraceptive use $(16,18,20,21)$. For example, in their study of sexual trajectories among Dutch adolescents and early adults, de Graff et al. (2009) found that women and men who followed a nonlinear trajectory more often had vaginal sex without using contraception despite reporting no desire to conceive a child (16). The investigators hypothesized that these relationships may reflect insufficient 
skills to plan safer sexual behavior (16). Other authors have also suggested that a temporal delay in progressing from lower-risk to higher-risk behaviors provides the time needed to become mentally prepared for contraception and to access contraceptive services (17). Although their findings are intriguing, these studies used different methodologies and vastly different, and homogenous, samples (i.e., young college students, 12-15 year old black and white adolescents in a large southern city in 1980, Dutch adolescents), and the generalizability of findings to various populations and contexts is not clear.

In the current study we investigate whether there is an association between sequences of sexual initiation during adolescence (defined here as initiating oral-genital sex or vaginal intercourse first) and the likelihood of subsequent teenage pregnancy using a nationally representative sample. Based on earlier work, we hypothesize that initiating oral-genital sex first, with a delay of at least one year to vaginal sex, would be associated with a lower likelihood of pregnancy before the age of 20 , relative to those who initiate vaginal sex first, even after adjustment for age at first sexual experience.

\section{Methods}

\section{Sample}

We used contractual data from Waves I and IV of the National Longitudinal Study of Adolescent Health (Add Health). Add Health is a prospective cohort study that has followed a nationally representative sample of U.S. adolescents into adulthood. From April to December of 1995, 20,745 Wave I in-home interviews were completed (79\% response rate, grades 7-12). At Wave I, a parent (usually the resident mother) also completed an interviewer-assisted questionnaire. Three follow-up interviews have been completed to date: Wave II (1996, grades 8-12, 88\% response rate.), Wave III (2001, ages 18 to 26, 77\% response rate), and Wave IV (2008, ages 24-32, 80\% response rate). See Harris et al. (2009) for a complete design description (22). All Add Health procedures were approved by the Public Health Institutional Review Board (IRB) at the University of North Carolina, Chapel Hill. Present analyses were deemed exempt from IRB review.

Our analysis sample was limited to female respondents who reported vaginal sex before the age of 20, were interviewed at both Waves I and IV, had a valid sample weight, and had complete data on sequence information, pregnancy history, and all other covariates ( $n=6,069,78 \%$ of Wave IV female respondents).

\section{Measures}

Because of their sensitive nature, all pregnancy and sexual behavior questions were selfadministered using computer-assisted self-interviewing (CASI).

Outcome: Teen Pregnancy-A complete pregnancy history for each respondent was collected during the Wave IV in-home interview. For each reported pregnancy, respondents recorded the month and year the pregnancy ended. Teen pregnancy was defined as having a pregnancy, regardless of the outcome, that ended before the age of 20.

Predictor: Sequence of sexual initiation-Questions about oral-genital and vaginal sexual experiences were also taken from the Wave IV in-home interview. Respondents were asked "Have you ever had vaginal intercourse? (Vaginal intercourse is when a man inserts his penis into a woman's vagina.)" and "Have you ever had oral sex? That is, has a partner ever put his/her mouth on your sex organs or you put your mouth on his/her sex organs?" If the respondents answered yes to either question, they were asked, "How old were you the very first time you had (that type of sex)?" We determined which behavior was experienced 
first based on the reported ages of initiation, and constructed three categories of sexual sequence initiation: vaginal sex first with a delay of at least one year to oral-genital sex, oral-genital sex first with a delay of at least one year to vaginal sex, and two behaviors within the same year (respondents reporting the same age for both vaginal and oral-genital sex). The few $(n=16)$ respondents who reported anal sex first with at a delay of at least one year to another type of sex were not included in the analysis sample due to small cell sizes.

Covariates-We adjusted for the following covariates:

Sociodemographic characteristics: Race/ethnicity was based on respondents' selfidentified race and Hispanic ethnicity, and was combined into five racial/ethnic categories: non-Hispanic white (reference category); Hispanic (any race); non-Hispanic black; nonHispanic Asian/Pacific Islander; and other. Parental education attainment, used as a proxy for socioeconomic status, consisted of the highest level of education obtained by either of the respondent's parents or caregivers (less than high school; high school graduate/GED; some college or post-high school business, trade, or vocational school; or college graduate or more (reference category)), and was reported by the resident mother in the parent Wave I in-home interview and supplemented by adolescent report if the parent information was missing. Family structure at the Wave I interview was based on respondents' reports of living with two biological parents (reference category), two parents where at least one is not biological, single mother, single father, or living in any other type of household structure. Respondent birth year captured cohort differences. Birth years ranged from 1974-1983, with the center 0 designated as 1979. Respondents born before 1979 received a negative value whereas respondents born after 1979 received a positive value. Values for respondent birth year ranged from -5 to 4 .

We also adjusted for neighborhood structural and social disadvantage. The associated social, psychological, and economic costs of neighborhood characteristics might have an effect of sexual behavior and teenage pregnancy (23). Structural disadvantage was determined by neighborhood poverty, defined as the proportion of families with dependents under age 18 with income below the poverty level in 1989, taken from the Add Health Wave I Contextual Data. A neighborhood with less than 11.6 percent of families below the poverty level was designated as low poverty; between $11.6 \%$ and $23.9 \%$ signified medium poverty; and greater than $23.9 \%$ signified high poverty (24). Values ranged from 1 to 3 , with higher values indicating greater neighborhood poverty. Social disadvantage was measured with two questions assessing neighborhood social ties and safety: "People in this neighborhood look out for one another" (true/false) and "Do you usually feel safe in your neighborhood?" (yes/ no). Answers were combined to create an aggregate measure of neighborhood social disadvantage, with scores ranging from 0-2. A score of 0 indicated not feeling safe in the neighborhood and no social ties; 1 indicated feeling safe with no social ties or not feeling safe with social ties; and a score of 2 indicated feeling safe in the neighborhood and social ties. Measures of neighborhood social disadvantage were taken from the Wave I in-home interview.

We controlled for a history of sexual abuse and parent-child relationship quality. Sexual abuse is thought to increase emotional distress and the risk of early sexual initiation as well as teen pregnancy (25). Sexual abuse (yes/no) was determined by the question, "Before your $18^{\text {th }}$ birthday, how often did a parent or other adult caregiver touch you in a sexual way, force you to touch him or her in a sexual way, or force you to have sexual relations?" An answer of one or more times was coded 1. Parent/child relationship quality is related to adolescent pregnancy risk in having an impact on delaying or reducing sexual intercourse (26). Parent-child relationship quality was measured by respondents' ratings of closeness, satisfaction with communication, overall relationship satisfaction, and the extent to which 
they felt their parent was warm and loving towards them; all questions used a five-point Likert scale for responses. Individual scores were calculated for each parent by summing responses across items. In cases where both parents are present in the household, the higher of the two scores was used. Values ranged from five to twenty, with higher values indicating greater quality.

We also controlled for age at first sexual experience, regardless of type of sex. We obtained the same pattern of results when controlling for age at first vaginal sex instead of and in addition to age at first sexual experience. Finally, we controlled for effective contraceptive usage, determined by whether the respondent had an unintended or intended first pregnancy ("Thinking back to the time just before this pregnancy with \{initials\}, did you want to have a child then?") and if she used contraception in the month before her first pregnancy ("In the month before you got pregnant were you or \{initials \} using any kind of birth control, including condoms?"). If a respondent had an unintended pregnancy, she was categorized as an ineffective contraceptor (regardless of reported contraceptive use). If a respondent had an intended pregnancy or had a history of sexual activity with no reported pregnancies, the respondent was categorized as an effective contraceptor. The latter category allowed for the inclusion of respondents for whom contraception was not directly measured in Wave IV.

\section{Statistical Analyses}

Multivariable logistic regression analysis tested whether reports of teen pregnancy differed according to sequence of sexual initiation (i.e., vaginal sex first, oral-genital sex first, or two behaviors in the same year), controlling for all covariates. Potential race/sequence interaction effects were tested separately. All analyses were weighted and adjusted to account for design effects.

\section{Results}

In our analysis sample, $78 \%$ of female respondents reported vaginal sex before the age of 20 and about $96 \%$ had had oral-genital sex before the age of 20 . Table 1 includes descriptive statistics by teen pregnancy status. Approximately one quarter of the analysis sample $(\mathrm{n}=1,519)$ reported a teen pregnancy. Vaginal sex preceded other behaviors for the majority of respondents. Approximately 55\% reported having vaginal sex first, $35 \%$ reported two behaviors in the same year, and $10 \%$ reported oral-genital sex first. Percentages reporting a teen pregnancy varied by sequence. Among females initiating vaginal sex first, approximately $31 \%$ reported a teen pregnancy. Among females initiating two behaviors at the same age, approximately $21 \%$ reported a teen pregnancy. Among females initiating oral sex first, only about $8 \%$ reported a teen pregnancy.

Table 2 presents results from the multivariate logistic regression model testing the association between sequences of sexual initiation and the likelihood of teenage pregnancy. Overall, engaging in oral-genital sex first or engaging in two sexual behaviors in the same year serve as protective factors against teenage pregnancy. Initiating oral-genital sex first, with a delay of at least one year to vaginal sex, is associated with a significantly lower likelihood of adolescent pregnancy, relative to teens who initiate vaginal sex first. Initiating two behaviors within the same year is also associated with a significantly lower likelihood of adolescent pregnancy, although the magnitude of association is smaller, relative to teens who initiate vaginal sex first.

Among the control variables, respondents were more likely to report a teen pregnancy if they were Hispanic, lived in a single-mother household or an "other" type of family structure at Wave I, or lived in a neighborhood with a high proportion of families under the poverty level. In contrast, respondents were less likely to have a teen pregnancy if they had a 
positive parent-child relationship, used contraceptives effectively, were older, and were older at the time of their first sexual experience, regardless of type of sex. Tests of interactions between race/ethnicity and sequence were not significant.

Figure 1 shows the predicted probabilities of a teen pregnancy by sequence of sexual initiation, with other variables held at their means. Respondents experiencing vaginal sex first have a $28 \%$ chance of having a teen pregnancy. Respondents experiencing two behaviors within the same year have a slightly lower chance (24\%) of having a teen pregnancy. In contrast, respondents experiencing oral-genital sex first and waiting at least a year to have vaginal sex have only about a $9 \%$ chance of having a teen pregnancy.

\section{Discussion}

This study examined whether there is an association between sequences of sexual initiation and the likelihood of teen pregnancy. We found that initiating vaginal sex first, and waiting at least a year until initiating oral-genital sex, was the most prevalent sequence in our sample of females, followed by initiating two behaviors in the same year, and finally initiating oralgenital sex first. Although Lindberg and colleagues (5) did not have data on age at oral sex in their NSFG analyses, our results are consistent with the patterns they found. However, they differ substantially from those reported by Song and Halpern-Felsher (8) for their longitudinal analysis of students in two California public high schools. In the California study, most sexually active adolescents initiated both vaginal and oral sex within the same 6month period, and of those reporting longer delays between initiation, oral sex usually occurred first. Differences in sample composition and methodology are likely contributing to these variant findings.

In this national sample of female adolescents who reported having vaginal sex before the age of 20, we found a significantly lower likelihood of pregnancy among females who initiated oral-genital sex first, and waited at least a year to progress to other behaviors, relative to teens who initiated vaginal sex first. Initiating two behaviors in the same year (versus initiating vaginal sex first) also significantly lowered the odds of a teen pregnancy; however the weaker association suggests that it is not only important to consider which type of sex is initiated first, but also the pace of moving to new experiences. For respondents who initiated two behaviors in the same year we cannot determine which behavior occurred first. Thus we are unable to directly assess the relative implications of sequence and delays of less than a year in behavior initiation.

The reasons underlying these associations are not yet clear. Initiating oral-genital sex first, negating the risk of pregnancy, and waiting at least a year to move on to other behaviors may allow adolescents time to develop better skills related to planning sexual encounters and negotiating contraception decisions with partners when they progress to vaginal intercourse. If so, they may be more likely to use contraceptives at first coitus, and as other research suggests (27), more likely to continue using contraceptives during later sexual activity. Further, as de Graff et al. (2009) suggest, getting started with oral-genital experiences may give adolescents more time to experiment and clarify their own desires and preferences (16), perhaps thereby increasing their sexual self-confidence.

Alternatively, certain teens may "select into" the group who begins their sexual experience with oral-genital sex. Although they may be underestimating some risks, adolescents perceive fewer negative health consequences from oral versus vaginal sex $(7,9-10,21)$. Adolescents who are motivated to avoid pregnancy and exposure to STIs (e.g., because of social and/or educational aspirations), may opt to engage in sexual activity that is perceived as safer, and to proceed at a slower pace to protect their future. This scenario suggests an 
endogenous process rather than benefits stemming directly from the choice to start with oralgenital sex per se, and is consistent with associations identified in the 2002 NSFG between intact families and better educated mothers on the one hand and a significantly higher likelihood of having had oral sex but not vaginal sex (7). Finally, there may be truth to both explanations. Adolescents with more ambitious future aspirations may opt into the behavior that is perceived as safer, and by taking that path, they gain time for safer experimentation and increasing maturity. Although beyond the scope of this paper, these questions should be addressed in future work that attempts to delineate pathways and mechanisms of effects.

\title{
Limitations
}

Our analyses have the strength of a large and diverse national sample. However our findings should be considered with certain limitations in mind. First, reports of ages of sexual initiation and pregnancy histories are retrospective, and are subject to recall error and bias. Further, since ages were reported in whole years we could not determine the initiation sequence for adolescents who reported two types of first sexual experiences at the same age. Third, due to data limitations, our measure of contraception conflates pregnancy intendedness and contraceptive behavior for some respondents. Finally, sexual behavior and pregnancy during adolescence are sensitive topics that may be under-reported, although the use of CASI should diminish these concerns.

\section{Conclusions}

Although there are limitations, our study is among the first to investigate the association between sequences of sexual initiation and the likelihood of teenage pregnancy using a large, population-based sample. Our findings suggest that how adolescents begin their sexual lives may have important implications for reproductive health outcomes. As others have noted, there is a need to include discussions of oral sex in sex education curricula (15), and to point out both the risks and the potential benefits when appropriate protection is used.

\section{Acknowledgments}

Effort by Halpern, Haydon, and Herring was supported by grant R01-HD57046, CT Halpern, Principal Investigator, from the Eunice Kennedy Shriver National Institute of Child Health and Human Development, and by grant 5 R24 HD050924, Carolina Population Center, awarded to the Carolina Population Center at The University of North Carolina at Chapel Hill by the Eunice Kennedy Shriver National Institute of Child Health and Human Development. Effort by Reese was supported by 3R01HD057046-01A2S1, a supplement.

\begin{abstract}
This research uses data from Add Health, a program project directed by Kathleen Mullan Harris and designed by J. Richard Udry, Peter S. Bearman, and Kathleen Mullan Harris at the University of North Carolina at Chapel Hill, and funded by grant P01-HD31921 from the Eunice Kennedy Shriver National Institute of Child Health and Human Development, with cooperative funding from 23 other federal agencies and foundations. Special acknowledgment is due Ronald R. Rindfuss and Barbara Entwisle for assistance in the original design. Information on how to obtain the Add Health data files is available on the Add Health website (http://www.cpc.unc.edu/addhealth). No direct support was received from grant P01-HD31921 for this analysis. At the time this work was conducted, A. A. Haydon was a doctoral student in the Department of Maternal and Child Health at the Gillings School of Global Public Health and a predoctoral trainee at the Carolina Population Center, both at the University of North Carolina at Chapel Hill.
\end{abstract}

\section{References}

(1). Hamilton BE, Martin JA, Ventura SJ. Division of Vital Statistics: Births: preliminary data for 2006. Vital Health Stat. 2007; 56:1-18.

(2). Centers for Disease Control and Prevention: CDC vital signs 2011. Office of Surveillance, Epidemiology and Laboratory Services; Atlanta, GA: 2011.

(3). Hoffman, SD. [Accessed September 21, 2011] By the numbers: the public costs of teen childbearing. Available at: http://www.thenationalcampaign.org/resources/pdf/pubs/btn_full.pdf 
(4). Mosher WD, Chandra A, Jones J. Sexual behavior and selected health measures: Men and women 15-44 years of age, United States, 2002. Vital Health Stat. 2005; 362

(5). Lindberg LD, Jones R, Santelli JS. Noncoital sexual activities among adolescents. J Adolesc Health. 2008; 43:231-238. [PubMed: 18710677]

(6). Ompad DC, Strathdee SA, Celentano DD, et al. Predictors of early initiation of vaginal and oral sex among urban young adults in Baltimore, Maryland. Arch Sex Behav. 2006; 35:53-65. [PubMed: 16502153]

(7). Brewster KL, Tillman KH. Who's doing it? Patterns and predictors of youths' oral sexual experiences. J Adolesc Health. 2008; 42:73-80. [PubMed: 18155033]

(8). Song AV, Halpern-Felsher BL. Predictive relationship between adolescent oral and vaginal sex results from a prospective, longitudinal study. Arch Pediatr Adolesc Med. 2011; 165:243-249. [PubMed: 21041589]

(9). Halpern-Felsher BL, Cornell JL, Kropp RY, et al. Oral versus vaginal sex among adolescents: perceptions, attitudes, and behavior. Pediatrics. 2005; 115:845-851. [PubMed: 15805354]

(10). Cornell JL, Halpern-Felsher BL. Adolescents tell us why teens have oral sex. J Adolesc Health. 2006; 38:299-301. [PubMed: 16488832]

(11). Uecker JE, Angotti N, Regnerus MD. Going most of the way: "Technical virginity” among American adolescents. Soc Sci Res. 2008; 37:1200-1215. [PubMed: 19227698]

(12). Chambers WC. Oral sex: Varied behaviors and perceptions in a college population. J Sex Res. 2007; 44:28-42. [PubMed: 17599262]

(13). Sanders SA, Reinisch JM. Would you say you "had sex" if ...? JAMA. 1999; 28:275-277. [PubMed: 9918484]

(14). Boekeloo BO, Howard DE. Oral sexual experience among young adolescents receiving general health examinations. Am J Health Behav. 2002; 26:306-314. [PubMed: 12081363]

(15). Halpern-Felsher B. Oral sexual behavior: Harm reduction or gateway behavior? J Adolesc Health. 2008; 43:207-208. [PubMed: 18710673]

(16). de Graaf H, Vanwesenbeeck I, Meijer S, et al. Sexual trajectories during adolescence: Relation to demographic characteristics and sexual risk. Arch Sex Behav. 2009; 38:276-282. [PubMed: 18165892]

(17). Smith EA, Udry JR. Coital and non-coital sexual behaviors of white and black adolescents. Am J Public Health. 1985; 75:1200-1203. [PubMed: 4037163]

(18). Hansen WB, Wolkenstein BH, Hahn GL. Young adult sexual behavior: issues in programming and evaluation. Health Educ Res. 1992; 7:305-312.

(19). Schwartz IM. Sexual activity prior to coital initiation: A comparison between males and females. Arch Sex Behav. 1999; 28:63-69. [PubMed: 10097805]

(20). Auslander BA, Biro FM, Succop PA, et al. Racial/ethnic differences in patterns of sexual behavior and STI risk among sexually experienced adolescent girls. J Pediatr Adolesc Gynecol. 2009; 22:33-39. [PubMed: 19232300]

(21). Brady SS, Halpern-Felsher BL. Adolescents' reported consequences of having oral sex versus vaginal sex. Pediatrics. 2007; 119:229-236. [PubMed: 17272611]

(22). Harris KM, Halpern CT, Whitsel E, et al. The National Longitudinal Study of Adolescent Health: Research Design. 1999 Available at: http://www.cpc.unc.edu/projects/addhealth/design.

(23). Cubbin C, Santelli J, Brindis CD, et al. Neighborhood context and sexual behaviors among adolescents: Findings from the National Longitudinal Study of Adolescent Health. Perspect Sex Reprod Health. 2005; 37:125-134. [PubMed: 16150660]

(24). Bureau of the Census: A Guide to State and Local Census Geography 1993. U.S. Government Printing Office; Washington, DC: 1993.

(25). Black MM, Oberlander SE, Lewis T, et al. Sexual intercourse among adolescents maltreated before age 12: A prospective investigation. Pediatrics. 2009; 124:941-949. [PubMed: 19706574]

(26). Miller BC, Benson B, Galbraith KA. Family relationships and adolescent pregnancy risk: A research synthesis. Developmental Review. 2001; 21:1-38. 
(27). Shafii T, Stovel K, Holmes K. Association between condom use at sexual debut and subsequent sexual trajectories: a longitudinal study using biomarkers. Am J Public Health. 2007; 97:10901095. [PubMed: 17463388] 


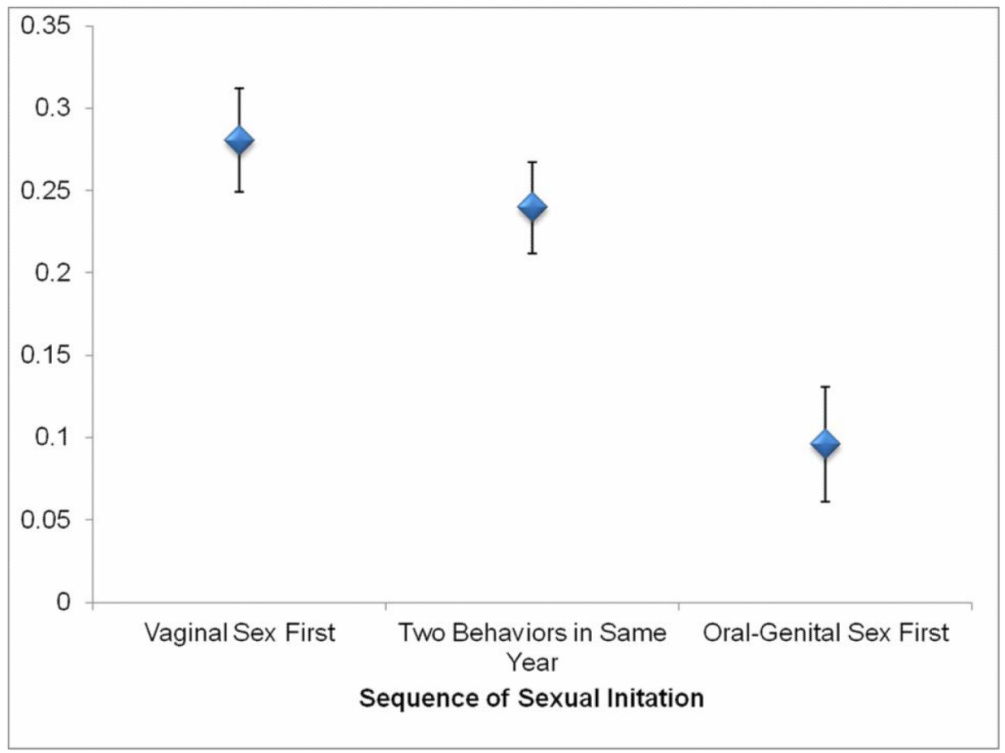

Figure 1.

Predicted probability (and 95\% CI) of teen pregnancy by sexual initiation category 
Table 1

Weighted frequency distributions of analysis sample across covariate categories, by teen pregnancy status

\begin{tabular}{|c|c|c|c|}
\hline \multirow[t]{2}{*}{ Variable } & \multirow{2}{*}{$\begin{array}{c}\text { Total } \\
\text { Sample } \\
(\mathbf{N}=6,069) \\
\%^{a} \\
\text { Mean (SE) }^{a}\end{array}$} & \multicolumn{2}{|c|}{ Teen Pregnancy Status } \\
\hline & & $\begin{array}{c}\text { No } \\
(\mathrm{N}=\mathbf{4 , 5 5 0})\end{array}$ & $\begin{array}{c}\text { Yes } \\
(\mathbf{N}=\mathbf{1 , 5 1 9})\end{array}$ \\
\hline Teen pregnancy & 25.2 & ------ & ----- \\
\hline \multicolumn{4}{|l|}{$\begin{array}{l}\text { Sequence of sexual } \\
\text { initiation }\end{array}$} \\
\hline Vaginal sex first & 54.7 & 68.6 & 31.4 \\
\hline Oral-genital sex first & 9.9 & 92.1 & 7.9 \\
\hline $\begin{array}{l}\text { Two behaviors at the } \\
\text { same age }\end{array}$ & 35.5 & 79.5 & 20.5 \\
\hline \multicolumn{4}{|l|}{ Race/ethnicity } \\
\hline Non-Hispanic white & 67.2 & 79.3 & 20.7 \\
\hline Non-Hispanic black & 16.7 & 63.3 & 36.1 \\
\hline Hispanic & 10.6 & 64.9 & 35.1 \\
\hline $\begin{array}{l}\text { Non-Hispanic } \\
\text { Asian/Pacific Islander }\end{array}$ & 2.94 & 77.2 & 22.8 \\
\hline Other race & 2.6 & 69.6 & 30.4 \\
\hline \multicolumn{4}{|l|}{ Family structure } \\
\hline Two biological parents & 51.2 & 81.7 & 18.3 \\
\hline Other two parent & 17.5 & 71.3 & 28.7 \\
\hline Single mother & 22.7 & 67.5 & 32.5 \\
\hline Single father & 2.4 & 74.4 & 25.6 \\
\hline Other family structure & 6.2 & 51.3 & 48.7 \\
\hline \multicolumn{4}{|l|}{$\begin{array}{l}\text { Highest parental } \\
\text { education }\end{array}$} \\
\hline Less than HS & 12.4 & 64.7 & 35.4 \\
\hline HS graduate/GED & 31.6 & 72.2 & 27.8 \\
\hline Some college & 22.0 & 76.2 & 23.8 \\
\hline $\begin{array}{l}\text { College graduate or } \\
\text { more }\end{array}$ & 28.2 & 85.0 & 15.0 \\
\hline Respondent birth year & $-.02(1.7)$ & ----- & ----- \\
\hline \multicolumn{4}{|l|}{ Neighborhood poverty } \\
\hline $\begin{array}{l}\text { Low Poverty (less than } \\
11.6 \% \text { ) }\end{array}$ & 51.6 & 79.5 & 20.5 \\
\hline $\begin{array}{l}\text { Medium Poverty } \\
\text { (between } 11.6 \% \text { and } \\
23.9 \% \text { ) }\end{array}$ & 24.9 & 74.9 & 25.1 \\
\hline $\begin{array}{l}\text { High Poverty (greater } \\
\text { than } 23.9 \% \text { ) }\end{array}$ & 23.5 & 64.5 & 35.5 \\
\hline \multicolumn{4}{|l|}{$\begin{array}{l}\text { Neighborhood social } \\
\text { disadvantage }\end{array}$} \\
\hline $\begin{array}{l}\text { Low Social } \\
\text { Disadvantage (0) }\end{array}$ & 66.9 & 76.8 & 23.2 \\
\hline $\begin{array}{l}\text { Medium Social } \\
\text { Disadvantage (1) }\end{array}$ & 27.0 & 71.6 & 28.4 \\
\hline
\end{tabular}




\begin{tabular}{|c|c|c|c|}
\hline \multirow[t]{2}{*}{ Variable } & \multirow{2}{*}{$\begin{array}{c}\text { Total } \\
\text { Sample } \\
(\mathrm{N}=6,069) \\
\%^{a} \\
\text { Mean (SE) }^{\text {(SE) }}\end{array}$} & \multicolumn{2}{|c|}{ Teen Pregnancy Status } \\
\hline & & $\begin{array}{c}\text { No } \\
(\mathrm{N}=\mathbf{4 , 5 5 0})\end{array}$ & $\begin{array}{c}\text { Yes } \\
(\mathbf{N}=\mathbf{1 , 5 1 9})\end{array}$ \\
\hline $\begin{array}{l}\text { High Social } \\
\text { Disadvantage (2) }\end{array}$ & 6.1 & 66.3 & 33.7 \\
\hline $\begin{array}{l}\text { Parent-child relationship } \\
\text { quality }\end{array}$ & $17.6(2.7)$ & ------ & ----- \\
\hline \multicolumn{4}{|l|}{ History of sexual abuse } \\
\hline $\begin{array}{l}\text { Sexual abuse reported } \\
\text { at least once }\end{array}$ & 7.9 & 62.6 & 37.4 \\
\hline $\begin{array}{l}\text { No reported sexual } \\
\text { abuse }\end{array}$ & 92.1 & 75.8 & 24.6 \\
\hline $\begin{array}{l}\text { Age at first sexual } \\
\text { experience }\end{array}$ & $16.5(2.9)$ & ----- & ------ \\
\hline \multicolumn{4}{|l|}{$\begin{array}{l}\text { Effective contraceptive } \\
\text { usage }\end{array}$} \\
\hline Effective contraceptor & 69.1 & 81.7 & 18.3 \\
\hline Ineffective contraceptor & 30.9 & 59.3 & 40.7 \\
\hline
\end{tabular}

${ }^{a}$ All percentages are adjusted for sampling probability; listed sample sizes are unweighted 
Table 2

Multivariate logistic regression analysis of factors associated with teen pregnancy

\begin{tabular}{|c|c|c|}
\hline Variable (Referent) & Adjusted OR & $\begin{array}{c}\text { Teen Pregnancy } \\
(95 \% \text { CI })\end{array}$ \\
\hline \multicolumn{3}{|l|}{$\begin{array}{l}\text { Sequence of sexual } \\
\text { initiation (Vaginal } \\
\text { sex first) }\end{array}$} \\
\hline $\begin{array}{l}\text { Oral-genital sex } \\
\text { first }\end{array}$ & $0.23^{* * * *}$ & $(0.15,0.37)$ \\
\hline $\begin{array}{l}\text { Two behaviors at } \\
\text { the same age }\end{array}$ & $0.74^{* *}$ & $(0.60,0.92)$ \\
\hline \multicolumn{3}{|l|}{$\begin{array}{l}\text { Race/Ethnicity (Non- } \\
\text { Hispanic white) }\end{array}$} \\
\hline Non-Hispanic black & 1.24 & $(0.96,1.67)$ \\
\hline Hispanic & $1.66^{* *}$ & $(1.23,2.23)$ \\
\hline Non-Hispanic & 1.16 & $(0.66,2.03)$ \\
\hline \multicolumn{3}{|l|}{$\begin{array}{l}\text { Asian/Pacific } \\
\text { Islander }\end{array}$} \\
\hline Other race & 1.31 & $(0.67,2.59)$ \\
\hline \multicolumn{3}{|l|}{$\begin{array}{l}\text { Family structure } \\
\text { (Two biological } \\
\text { parents) }\end{array}$} \\
\hline Other two parent & 1.68 & $(0.84,3.35)$ \\
\hline Single mother & $1.42^{* * * *}$ & $(1.15,1.75)$ \\
\hline Single father & 1.07 & $(0.59,1.92)$ \\
\hline $\begin{array}{l}\text { Other family } \\
\text { structure }\end{array}$ & $3.36^{* * *}$ & $(2.31,4.88)$ \\
\hline \multicolumn{3}{|l|}{$\begin{array}{l}\text { Highest parental } \\
\text { education (College } \\
\text { graduate or more) }\end{array}$} \\
\hline $\begin{array}{l}\text { Less than high } \\
\text { school }\end{array}$ & 1.33 & $(0.90,1.96)$ \\
\hline $\begin{array}{l}\text { High school } \\
\text { graduate/GED }\end{array}$ & 1.23 & $(0.98,1.56)$ \\
\hline Some college & 1.12 & $(0.86,1.46)$ \\
\hline $\begin{array}{l}\text { Respondent birth } \\
\text { year }\end{array}$ & $1.08^{* * *}$ & $(1.02,1.13)$ \\
\hline $\begin{array}{l}\text { Neighborhood } \\
\text { poverty }\end{array}$ & $1.19^{* * *}$ & $(1.05,1.35)$ \\
\hline $\begin{array}{l}\text { Neighborhood social } \\
\text { disadvantage }\end{array}$ & 0.94 & $(0.81,1.10)$ \\
\hline $\begin{array}{l}\text { Parent-child } \\
\text { relationship quality }\end{array}$ & $0.96^{*}$ & $(0.94,0.99)$ \\
\hline $\begin{array}{l}\text { History of sexual } \\
\text { abuse }\end{array}$ & 1.15 & $(0.83,1.58)$ \\
\hline $\begin{array}{l}\text { Age at first sexual } \\
\text { experience }\end{array}$ & $0.79^{* * * *}$ & $(0.75,0.85)$ \\
\hline $\begin{array}{l}\text { Effective } \\
\text { contraceptive usage }\end{array}$ & $0.39^{* * * *}$ & $(0.32,0.47)$ \\
\hline
\end{tabular}

Estimates are based on weighted data.

$\mathrm{p}<0.05$ 
*** $<<0.01$

p $<0.001$ 